\begin{tabular}{|c|c|}
\hline Title & $\begin{array}{l}\text { Risk Factors of Eclampsia Other Than Hypertension : Pregnancy-Induced A ntithrombin Deficiency and Extraordinary } \\
\text { Weight Gain }\end{array}$ \\
\hline Author(s) & $\begin{array}{l}\text { Y amada, Takashi; Kuwata, Tomoyuki; Matsuda, Hideo; Deguchi, Keizo; Morikawa, Mamoru; Y amada, Takahiro; } \\
\text { Furuya, Kennichi; Matsubara, Shigeki; Minakami, Hisanori }\end{array}$ \\
\hline Citation & $\begin{array}{l}\text { Hy pertension in Pregnancy, 31(2), 268-277 } \\
\text { https://doi.org/10.3109/10641955.2011.638957 }\end{array}$ \\
\hline Issue Date & $2012-05$ \\
\hline Doc URL & http:/hdl.handle.net/2115/53276 \\
\hline Type & article (author version) \\
\hline File Information & Hypertens Pregnancy_31(2)_268-277.pdf \\
\hline
\end{tabular}

Instructions for use 
[ORIGINAL ARTICLE]

\section{Risk factors of eclampsia other than hypertension: pregnancy-induced antithrombin deficiency and extraordinary weight gain}

Takashi Yamada ${ }^{1} *, \mathrm{MD}, \mathrm{PhD}$ : Corresponding author and data analysis

Tomoyuki Kuwata ${ }^{2)}$, MD, PhD: Data sampling

Hideo Matsuda ${ }^{3)}$, MD, PhD: Data sampling

Keizo Deguchi ${ }^{4)}$, MD: Data sampling

Mamoru Morikawa $^{1)}$, MD, PhD: Data analysis

Takahiro Yamada ${ }^{1)}$, MD, PhD: Data sampling

Kennichi Furuya ${ }^{3)}$, MD, PhD: Adviser

Shigeki Matsubara ${ }^{2)}$, MD, PhD: Adviser

Hisanori Minakami ${ }^{1)}$, MD, PhD: Director and institutional reviewer

*Corresponding author

${ }^{1)}$ Department of Obstetrics, Hokkaido University Graduate School of Medicine, Kita-ku

N14 W6, Sapporo 060-8638, Japan

${ }^{2)}$ Department of Obstetrics and Gynecology, Jichi Medical University School of Medicine, Tochigi, Japan

${ }^{3)}$ National Defense Medical College, Saitama, Japan

${ }^{4)}$ Sapporo Toho Hospital, Sapporo, Japan 


\begin{abstract}
OBJECTIVE: Recent findings suggest that cerebral edema is a characteristic finding on magnetic resonance imaging (MRI) in women with eclampsia and that pregnancy-induced antithrombin deficiency (PIATD) may reflect enhanced vascular permeability and may allow the retention of excess water in the interstitial space. Whether PIATD and extraordinary weight gain (EOWG) are risk factors for eclampsia remains to be studied.
\end{abstract}

METHODS: The medical records of 11 women with eclampsia among 17,522 deliveries were reviewed retrospectively with respect to changes in the laboratory data and the maternal body weight. PIATD was defined as a perinatal antithrombin activity $\leq$ $65 \%$ of the normal activity levels with an antenatal decline and/or a prompt postnatal increase. A large net weight gain during the last two antenatal weeks $>97.5^{\text {th }}$ percentile value (> 4.01kg) obtained from 272 control women with neither hypertension nor PIATD was defined as EOWG. Relative risk (RR) was obtained on the assumption that the prevalences of PIATD and EOWG were $2.0 \%$ and $2.5 \%$, respectively, among 17,511 women who did not develop eclampsia.

RESULTS: The duration of hypertension until an eclamptic fit was within 7 days in all 11 cases. PIATD and EOWG were observed in $6(54.5 \%)$ and $2(18.2 \%)$ cases, yielding an RR (95\% confidential interval) of $57.9(17.7-188.7)$ and $8.65(1.87-39.91)$ for eclampsia among women with PIATD and EOWG, respectively.

CONCLUSIONS: PIATD and EOWG may be risk factors for eclampsia.

(Key words: eclampsia, edema, pregnancy-induced antithrombin deficiency) 


\section{Introduction}

Current criteria for pregnancy-induced hypertension define pregnancy-induced hypertension as hypertension with or without proteinuria occurring at or after 20 weeks of gestation but resolving by 12 weeks postpartum [18]. Based on these criteria, women with edema and/or proteinuria alone are not diagnosed as having pregnancy-induced hypertension until they exhibit additional hypertension. However, absolute blood pressure alone is not always a dependable indicator of the severity of preeclampsia, because some women with proteinuria alone develop life-threatening eclampsia $[2,5,7$, 11]. Approximately $20 \%$ to $50 \%$ of women do not have hypertension at their last antenatal visit within a week before their first convulsive fit $[2,7,11]$. Similarly, a case of a woman who exhibited edema alone but who eventually progressed to a serious clinical condition has been documented [8]. Therefore, new clinical or laboratory parameters other than hypertension are needed to predict and prevent the occurrence of eclampsia.

Some women develop a gradual decline in antithrombin (AT) activity during the late stage of pregnancy, even in the absence of hypertension $[12,13,25]$. This decline in AT activity continues until the day of or one day after delivery, and a prompt normalization of AT activity occurs postpartum in such patients with pregnancy-induced AT deficiency (PIATD) [13]. The incidence of PIATD, defined as a gradual decline in antithrombin activity to $\leq 65 \%$ of the normal activity levels, is approximately $20 \%$ among women with PIH [17] and approximately 1.0\% among women with otherwise healthy singleton pregnancies $[17,26]$, and women with PIATD are likely to develop perinatal liver dysfunction [13]. Liver dysfunction with transient thrombocytopenia and a transient elevation in serum LDH, namely HELLP syndrome, is considered to be a severe 
condition irrespective of the degree of hypertension [18]. Patients with edema and/or PIATD may be at an increased risk of developing eclampsia irrespective of the degree of hypertension based on the following reasons: (i) edema can result from enhanced vascular permeability [6]; (ii) cerebral edema is a characteristic finding on magnetic resonance imaging (MRI) in patients with eclampsia [4, 10, 23]; (iii) vascular permeability is thought to be enhanced in patients with PIATD [8, 17]; (iv) a lower antithrombin activity possibly reflects an enhanced vascular permeability $[8,16,17]$; and (v) patients with either PIATD or eclampsia are likely to develop HELLP syndrome $[13,20]$. Accordingly, we conducted this retrospective study to determine whether women with eclampsia are likely to exhibit PIATD and/or abnormal weight gain prior to an eclamptic fit.

\section{Methods}

This study was conducted retrospectively after approval by the institutional review board at Hokkaido University Hospital. Patients with a diagnosis of eclampsia were selected from amongst 17,522 women who had received antenatal care and given birth during the 67-month period between January 2005 and September 2010 at four hospitals: Sapporo Toho Hospital, Jichi Medical School Hospital, National Defense Medical College Hospital, and Hokkaido University Hospital. The medical records of these women with eclampsia were reviewed retrospectively with respect to changes in laboratory data and maternal body weight during pregnancy and postpartum. Patients who were referred to those hospitals after an eclamptic fit were excluded from the present analyses.

Women who developed hypertension (systolic blood pressure $\geq 140 \mathrm{mmHg}$ or 
diastolic blood pressure $\geq 90 \mathrm{mmHg}$ ) alone, proteinuria $(\geq 0.3 \mathrm{~g} / \mathrm{day}$ ) alone, or both hypertension and proteinuria at $\geq 20$ weeks of gestation were diagnosed as having gestational hypertension, gestational proteinuria, and preeclampsia, respectively. A positive spot urine test result $(\geq 2+)$ or a protein concentration in the urine of $\geq 25$ $\mathrm{mg} / \mathrm{dL}$ was considered to indicate significant proteinuria $(\geq 0.3 \mathrm{~g} /$ day $)$. Pregnancy-induced antithrombin deficiency (PIATD) was defined as a gradual decline in antithrombin (AT) activity to $\leq 65 \%$ of the normal activity levels or a perinatal AT activity level of $\leq 65 \%$, with a prompt increase after delivery.

Data on antenatal AT activity were not available in the majority of 17,522 women. Therefore, maternal body weight was examined prospectively at two weeks prior to delivery, on the day of delivery, and one and four weeks postpartum in 272 women who developed neither hypertension nor PIATD and consecutively gave birth to a singleton term infant (age and gestational week at delivery, 30.8 \pm 5.2 years old and 38.1 \pm 1.8 , respectively) at Hokkaido University Hospital between January 1, 2009 and June 30, 2010 to determine the normal changes in maternal body weight among women with neither hypertension nor PIATD. Pre-pregnancy body weight, weight gain during pregnancy, and body weight at delivery were $53.8 \pm 11.0 \mathrm{~kg}, 9.7 \pm 4.0 \mathrm{~kg}$, and $63.5 \pm$ $4.0 \mathrm{~kg}$, respectively. Cesarean delivery rate was $40.1 \%$ in these 272 women. The net changes in body weight from the day of delivery were calculated in these 272 women. Women who exhibited a larger $\left(>97.5^{\text {th }}\right.$ percentile) net change in body weight during the last two antenatal weeks were judged as having extraordinary weight gain (EOWG).

PIATD occurs in approximately $20 \%$ of women with pregnancy-induced hypertension [17] and in approximately $1.0 \%$ of women with otherwise healthy singleton pregnancies $[17,26]$. Since pregnancy-induced hypertension occurs in 
approximately $5.0 \%$ of women with singleton pregnancies, PIATD occurs in approximately $2.0 \%$ of general pregnant women with singleton pregnancies. Since information on the antenatal weight gain and perinatal AT activity were not available in the majority of the 17,511 women who did not develop eclampsia in this study, we assumed that the prevalence of PIATD would be $2.0 \%$ among these 17,511 women and that the $97.5^{\text {th }}$ percentile value for the net weight gain during the last two antenatal weeks obtained from 272 control women would be applicable to these 17,511 women. Then, the relative risk (RR) and 95\% confidence interval $(95 \% \mathrm{CI})$ for developing eclampsia was calculated among women with PIATD or EOWG.

Statistical analyses were performed using the JMP8 statistical software package (SAS, Cary, NC). Differences in the means were tested using the Tukey-Kramer HSD (honestly significant difference) test between each group, and categorical variables were compared using the Fisher exact test. A P value of less than 0.05 was considered to indicate statistical significance.

\section{Results}

Among the 17,522 women who gave birth at four hospitals during the study period, 11 women developed eclampsia (Table 1), resulting in an incidence of 1 in 1,593 women. Nulliparous women accounted for $72.7 \%(8 / 11)$ of the cases. The antenatal diagnosis was preeclampsia in 6 cases and gestational hypertension in 4 cases. However, hypertension was first observed on the day of the eclamptic fit in five cases (Cases 5, 8-11), one day prior to the fit in two cases (Cases 3 and 6), and three, four and six days prior to the fit in one case each (Cases 7, 2 and 1, respectively). Hypertension was not recognized until the eclamptic fit in one case (Case 4). Thus, the time interval after the 
diagnosis of hypertension until the eclamptic fit was within 7 days in all the cases.

PIATD was observed in $6(54.5 \%)$ of the 11 cases (Table 1). An antenatal decline in the AT activity was observed in three cases (Cases 1, 2, and 3) (Fig. 1). Although the antenatal AT activity was not available in the other three women with PIATD (Cases 4, 6, and 8), a prompt postnatal increase in AT activity was observed. In the other five women without PIATD, the lowest AT activity was $72 \%, 77 \%$, and $82 \%$ on the day of delivery for Cases 5, 7, and 9, respectively, $89 \%$ on postpartum day 4 for Case 10, and $89 \%$ at one day prior to delivery for Case 11.

In the control group, comprised of 272 women with neither PIATD nor hypertension, the antenatal weight gain (median) during the last two weeks was $0.76 \mathrm{~kg}\left[2.5^{\text {th }}-97.5^{\text {th }}\right.$ percentile value: $-1.66 \mathrm{~kg}-4.01 \mathrm{~kg}]$, and the postnatal weight loss was $4.70 \mathrm{~kg}[0.40 \mathrm{~kg}$ $-9.20 \mathrm{~kg}]$ and $7.55 \mathrm{~kg}[3.05 \mathrm{~kg}-12.82 \mathrm{~kg}]$ on postpartum days 7 and 28 , respectively [shadow area in Fig. 2]. Six women with EOWG $\left(>97.5^{\text {th }}\right.$ percentile weight gain during the last two antenatal weeks, $>4.01 \mathrm{~kg}$ ) exhibited a weight gain of $6.2 \pm 2.2 \mathrm{~kg}$ (mean \pm SD) during the last two antenatal weeks and a significantly larger weight loss of $11.1 \pm$ $5.1 \mathrm{~kg}$ during the 4 weeks postpartum, compared with the other women with a smaller antenatal weight gain (Table 2). Two (18.2\%) of the 11 cases (Cases 1 and 2) exhibited a larger antenatal weight gain during the last two antenatal weeks (Fig. 2) exceeding the $97.5^{\text {th }}$ percentile value $(>4.01 \mathrm{~kg}$ ) of the control women and were judged to have EOWG.

The number of women with PIATD would be $350(2.0 \%$ of 17,511) among 17,511 women without eclampsia, based on the assumption described in the Methods section, and 6 among the 11 cases in this study. Thus, the frequency of eclampsia would be $1.7 \%$ (6/356) for women with PIATD and $0.029 \%(5 / 17,166)$ for women without PIATD, 
yielding an RR $(95 \% \mathrm{CI})$ of $57.9(17.7$ - 188.7) for the development of eclampsia among women with PIATD, compared with women without PIATD. The number of women with EOWG (antenatal weight gain during the last two antenatal weeks $>4.01 \mathrm{~kg}$ ) would be $437(2.5 \%$ of 17,511$)$ among the 17,511 women without eclampsia, based on the assumption described in the Methods section, and 2 among the 11 cases in this study. Thus, the frequency of eclampsia would be $0.46 \%$ (2/439) for women with EOWG and $0.053 \%(9 / 17,083)$ for women without EOWG, yielding an RR $(95 \% \mathrm{CI})$ of $8.65(1.87-$ 39.91) for the development of eclampsia among women with EOWG, compared with women without EOWG.

\section{Discussion}

PIATD was observed in $54.5 \%(6 / 11)$ of the women with eclampsia in this study. Since PIATD occurs less frequently among women without eclampsia, i.e., in approximately $20 \%$ of women with pregnancy-induced hypertension [17] and in approximately $1.0 \%$ of women with otherwise healthy singleton pregnancies $[17,26]$, this study suggests that women with PIATD are likely to experience an eclamptic fit, supporting our hypothesis. If we assumed that the general incidence of PIATD would be 2.0\%, women with PIATD would have a 58-fold higher risk (95\%CI, $17.7-188.7)$ of developing eclampsia, compared with women without PIATD, suggesting that PIATD is a risk factor for eclampsia.

EOWG defined as an antenatal weight gain during the last two antenatal weeks > $4.01 \mathrm{~kg}$ was observed in two of the 11 cases in the present study, suggesting that women with EOWG are likely to experience an eclamptic fit. If we assume that the $97.5^{\text {th }}$ percentile value of the net weight gain $(>4.01 \mathrm{~kg})$ during the last two antenatal weeks 
obtained from 272 control women would be applicable to general pregnant women without eclampsia, women with EOWG had an 8.7-fold higher risk (95\%CI, 1.87 39.91) of developing eclampsia, compared with women without EOWG, in this study. In addition, women with a larger weight gain of $>97.5^{\text {th }}$ percentile value during the last two antenatal weeks exhibited a significantly larger weight loss during the first four postnatal weeks than the other women (Table 2, Fig. 2). Since excessive weight gain during the last two antenatal weeks and postnatal excessive weight loss indicate edema arising from the accumulation of excess water in the interstitial space, this study suggests that marked edema during the final stage of pregnancy is a risk factor for eclampsia.

PIATD, marked edema, and eclampsia may be related to each other pathogenetically. An increase in water retention is a normal physiological alteration during pregnancy. Clearly demonstrable pitting edema of the ankles and legs is seen in most pregnant women, especially during the late stages of pregnancy [1]. Edema resulting from the retention of excess water in the interstitial space can be massive in women with pregnancy-induced hypertension, mainly because of the increased blood vessel permeability [3, 19], and usually results in hemoconcentration and a decrease in the circulating plasma volume in patients with pregnancy-induced hypertension [21, 22]. The process involved in the retention of water is reversed by parturition, and excess water in the interstitial space returns into the intravascular space, resulting in a fall in the hematocrit value and the excretion of the excess water in the urine. This enables the edema to resolve. The extent of the postpartum decrease in the hematocrit value may therefore reflect the degree of antenatal hemoconcentration and the decrease in the circulating plasma volume. Women with PIATD show a large postnatal decrease in the 
hematocrit value, irrespective of the presence or absence of hypertension, suggesting the antenatal presence of increased blood vessel permeability and hemoconcentration in women with PIATD [17]. On the other hand, a considerable amount of antithrombin is detected in the ascites of pregnant women with generalized edema, suggesting that antithrombin escapes from the blood into the interstitial space in the presence of the increased blood vessel permeability [16]. This phenomenon partially explains the gradual decline in antithrombin activity in women with PIATD. In addition, since enhanced coagulation-fibrinolysis is notable characteristics in women with PIATD showing perinatal increase in D-dimer and perinatal decrease in fibrinogen [15], enhanced coagulation-fibrinolysis also contributes to PIATD. Thus, PIATD and edema are related to each other through a common background of increased blood vessel permeability, and antithrombin activity may reflect the degree of vascular permeability. Indeed, two of the six women with PIATD exhibited EOWG in this study. The posterior reversible encephalopathy syndrome seen on MRI findings obtained in Cases 1 and 2 is a characteristic finding frequently seen in patients with eclampsia $[10,23]$ and represents subcortical edema without infarction [4]. Although the precise mechanisms involved in the formation of subcortical edema are unknown, the increased blood vessel permeability may contribute to the formation of subcortical edema, similar to the mechanisms involved in generalized edema and PIATD.

Proteinuria developed in 6 patients with eclampsia at the same time point when hypertension developed in the present study. Some patients with isolated proteinuria subsequently develop hypertension $[14,15]$ and proteinuria alone may also be associated with the decrease in AT activity; in comparison with 19 women diagnosed as having proteinuria preceding preeclampsia and 18 women diagnosed as having 
gestational proteinuria at 12 weeks postpartum, significant differences are observed in AT activity (77.4 $\pm 13.0 \%$ vs. $89.7 \pm 8.4 \%$, respectively) and the rate of AT activity $<70 \%$ ( $42.1 \%$ vs. $22.2 \%$, respectively) [15]. Since AT activity is $106 \pm 12 \%$ at $36.8 \pm 1.2$ weeks of gestation in 663 women with singleton pregnancies in the absence of preeclampsia and the rate of AT activity $<80 \%$ is less than $5.0 \%$ [25], AT activity of $89.7 \pm 8.4 \%$ and the rate of AT activity $<70 \%(22.2 \%)$ in the 18 women with gestational proteinuria [15] appear to be lower and higher than corresponding figures, respectively in women without proteinuria.

The present study included only women who had received antenatal care and given birth at four secondary or tertiary hospitals (one secondary hospital and three university hospitals). This may explain why there were no women with eclamptic fit before 36 weeks of gestation in the present study because these hospitals generally provide more intensive cares for complicated women than general obstetrical institutions. Although not verified, it is possible that women who develop eclamptic fit at preterm exhibit hypertension for longer time compared with women who develop eclamptic fit at term. As previously mentioned, the duration of hypertension until the eclamptic fit was relatively short; the time interval after the diagnosis of hypertension until the eclamptic fit was within 7 days in all 11 cases in this study. In studies performed in the United Kingdom, hypertension was absent in 68 of 325 (21\%) women with eclampsia in 1992 [2] and in 113 of 214 (53\%) women with eclampsia between February 2005 and February 2006 at the time of their last antenatal visit and within 1 week of their first convulsion [7]. In a study performed in Japan in 2004, pregnancy-induced hypertension was not diagnosed before the eclamptic fit in 30 of the 54 (56\%) women with eclampsia [11]. In Sweden, during 1991-1992, the incidence rate of eclampsia $(3.3 / 10,000$ 
pregnancies) increased significantly compared with the incidence

pregnancies) in 1976-1980 [9], raising the question of whether the incidence of eclampsia can be reduced by the earlier diagnosis and treatment of preeclampsia. As already described, the diagnosis of pregnancy-induced hypertension is not made in approximately $50 \%$ of women who develop eclampsia. This suggests the need for physical and/or laboratory parameters other than hypertension to predict the development of and thereby prevent the occurrence of eclampsia. The monitoring of weight gain during the late stage of pregnancy and the measurement of antithrombin activity in women with excessive weight gain may be helpful for detecting women with a high risk of eclampsia.

Extraordinary weight gain defined as an antenatal weight gain during the last two antenatal weeks $>4.01 \mathrm{~kg}$ necessarily reflected excessive water retention and was assessed easily and objectively in the present study. Despite the elimination of edema as a diagnostic criteria for preeclampsia in many countries and the fact that edema can occur in normal pregnancy [24], the present study suggested that excessive water retention was a physical risk factor for eclampsia. The close attention to weight gain at term may be helpful for the detection of women at high risk of developing eclampsia. Since antithrombin escapes from the blood into the interstitial space in the presence of increased blood vessel permeability [14, 15], antithrombin activity may reflect the degree of blood vessel permeability. The present study suggested that pregnancy-induced antithrombin deficiency was a laboratory risk factor for eclampsia. However, this study dealt with only a small number of women with eclampsia. A larger and well-controlled study is clearly needed to confirm our results. 


\section{References}

[1] Cunningham FG, Leveno KJ, Bloom SL, Hauth JC, Gilstrap III LC, Wenstrom KD: Maternal physiology, In; Williams Obstetrics $22^{\text {nd }}$ ed., McGraw-Hill, New York; 2005, pp. $122-50$.

[2] Douglas KA, Redman CWG: Eclampsia in the United Kingdom. BMJ 1994; 309: $1395-1400$.

[3] Haller H, Hempel A, Houmuth V, Mandelkow A, Busjahn A, Maasch C, Drab M, Lindschau C, Jupner A, Vetter K, Dudenhausen J, Luft FC: Endothelial-cell permeability and protein kinase $\mathrm{C}$ in pre-eclampsia. Lancet 1998; 351: 945-949

[4] Hinchey J, Chaves C, Appignani B, Breen J, Pao L, Wang A, Pessin MS, Lamy C, Mas J-L, Caplan LR: A reversible leukoencephalopathy syndrome. N Engl J Med 1996; 334: 494-500.

[5] Hypertensive disorders in pregnancy: In Williams Obstetrics, 22nd ed. (Eds, Cunningham FG et al), Chapter 34, p764, McGraw-Hill, New York

[6] Hypertensive disorders in pregnancy: In Williams Obstetrics, 22nd ed. (Eds, Cunningham FG et al), Chapter 34, p771-772, McGraw-Hill, New York

[7] Knight M on behalf of UKOSS: Eclampsia in the United Kingdom 2005. Br J Obstet Gynaecol 2007; 114: 1072-1078.

[8] Koyama T, Yamada T, Morikawa M, Tanaka R, Yamamura M, Araki N, Yamada T, Shimada S, Minamai H: Marked gestational edema as a clinical sign of life-threatening condition. J Obstet Gynaecol Res 2010; 36: 861-865.

[9] Kullberg G, Lindeberg S, Hanson U: Eclampsia in Sweden. Hypertens Preg 2002; 21: $13-21$.

[10] Matsuda H, Sakaguchi K, Shibasaki T, Takahashi H, Kawakami Y, Furuya K, 
Kikuchi Y: Cerebral edema on MRI in severe preeclamptic women developing eclampsia. J Perinat Med 2005; 33: 199-205.

[11] Minakami H, Kubo T, Takeda S, Kawabata M, Kobayashi T, Nakabayashi M: Placental abruption, HELLP syndrome, and Eclampsia in Japan. Nippon Sanka-Fujinka Gakkai Zasshi 2009; 61: 1559-1567.

[12] Minakami H, Morikawa M, Yamada T, Yamada T: Candidates for the determination of antithrombin activity in pregnant women. J Perinat Med, in press

[13] Minakami H, Watanabe T, Izumi A, Matsubara S, Koike T, Sayama M, Moriyama I, Sato I: Association of a decrease in antithrombin III activity with a perinatal elevation in aspartate aminotransferase in women with twin pregnancies: relevance to the HELLP syndrome. J Hepatol. 1999; 30: 603-611.

[14] Morikawa M, Yamada T, Minakami H. Outocme of pregnancy with isolated proteinuria. Curr Opin Obstet Gynecol 2009; 21: 491-495.

[15] Morikawa M, Yamada T, Yamada T, Cho K, Yamada H, Sakuragi N, Minakami H. Pregnancy outcome of women who developed proteinuria in the absence of hypertension after mid-gestation. J Perinat Med 2008; 36: 419-424.

[16] Morikawa M, Yamada T, Yamada T, Koyama T, Akaishi R, Takeda M, Araki N, Cho K, Minakami H: Evidence of the escape of antithrombin from the blood into the interstitial space in pregnant women. J Perinat Med 2010; 38: 613-615

[17] Morikawa M, Yamada T, Yamada T, Shimada S, Koyama T, Yamada H, Cho K, Minakami H: Pregnancy-induced antithrombin deficiency. J Perinat Med 2010; 38: $379-385$.

[18] Report of the National High Blood Pressure Education Program Working Group on High Blood Pressure in Pregnancy. Am J Obstet Gynecol. 2000;183: S1-22. 
[19] Roberts JM, Taylor RN, Musci TJ, Rodgers GM, Hubel CA, McLaughlin MK: Preeclampsia: an endothelial cell disorder. Am J Obstet Gynecol 1989; 161: 1200-1204. [20] Sibai BM, Taslimi MM, El-Nazer A, Amon E, Mabie BC, Ryan GM: Maternal-perinatal outcome associated with the syndrome of hemolysis, elevated liver enzymes, and low platelets in severe preeclampsia-eclampsia. Am J Obstet Gynecol 1986; 155: 501-509.

[21] Silver HM, Seebeck MA, Carlson R: Comparison of total blood volume in normal, preeclamptic, and nonproteinuric gestational hypertensive pregnancy by simultaneous measurement of red blood cell and plasma volumes. Am J Obstet Gynecol 1998; 179: 87-93.

[22] Soffronoff EC, Kaufmann BM, Connaughton JF: Intravascular volume determinations and fetal outcome in hypertensive diseases of pregnancy. Am J Obstet Gynecol 1977; 127: 4-9.

[23] Thomas SV: Neurological aspects of eclampsia. J Neurol Sci 1998; 155: 37-43.

[24] Thomson AM, Hytten FE, Billewicz WZ: Epidemiology of oedema during pregnancy. J Obstet Gynaecol Br Commonwealth 1967; 74: 1-10.

[25] Tsunoda T, Ohkuchi A, Izumi A, Watanabe T, Matsubara S, Sato I, Minakami H: Antithrombin III activity and platelet count are more likely to decrease in twin pregnancies than in singleton pregnancies. Acta Obstet Gynecol Scand 2002; 81: $840-845$.

[26] Minakami H, Morikawa M, Shimada S, Yamada T, Tho K, Koyama T, Mizushima M, Yamada T. Pregnancy-induced antithrombin deficiency. Jpn J Obstet Gynecol Neonatol Hematol 2010; 19: 7-17 (in Japanese). 


\section{Figure Legends}

Figure 1: Perinatal changes in antithrombin activity in 6 women who developed eclampsia and pregnancy-induced antithrombin deficiency.

Figure 2: Perinatal changes in maternal body weight in two women who developed eclampsia and extraordinary weight gain. The shaded area indicates the range of the $2.5^{\text {th }}-97.5^{\text {th }}$ percentile value obtained from 272 control women with neither hypertension nor pregnancy-induced antithrombin deficiency. The dotted line in the center of the shaded area indicates the median value. 


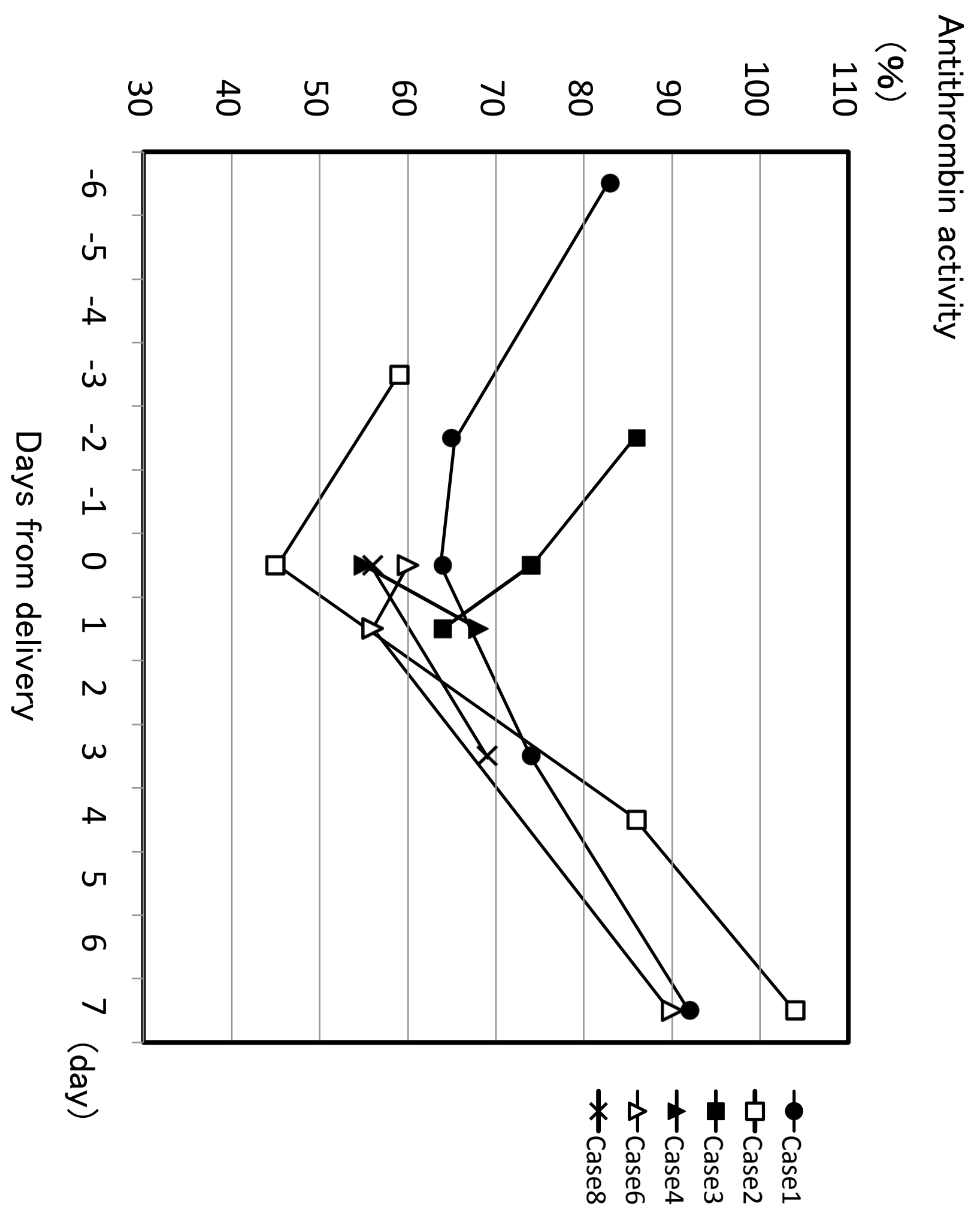




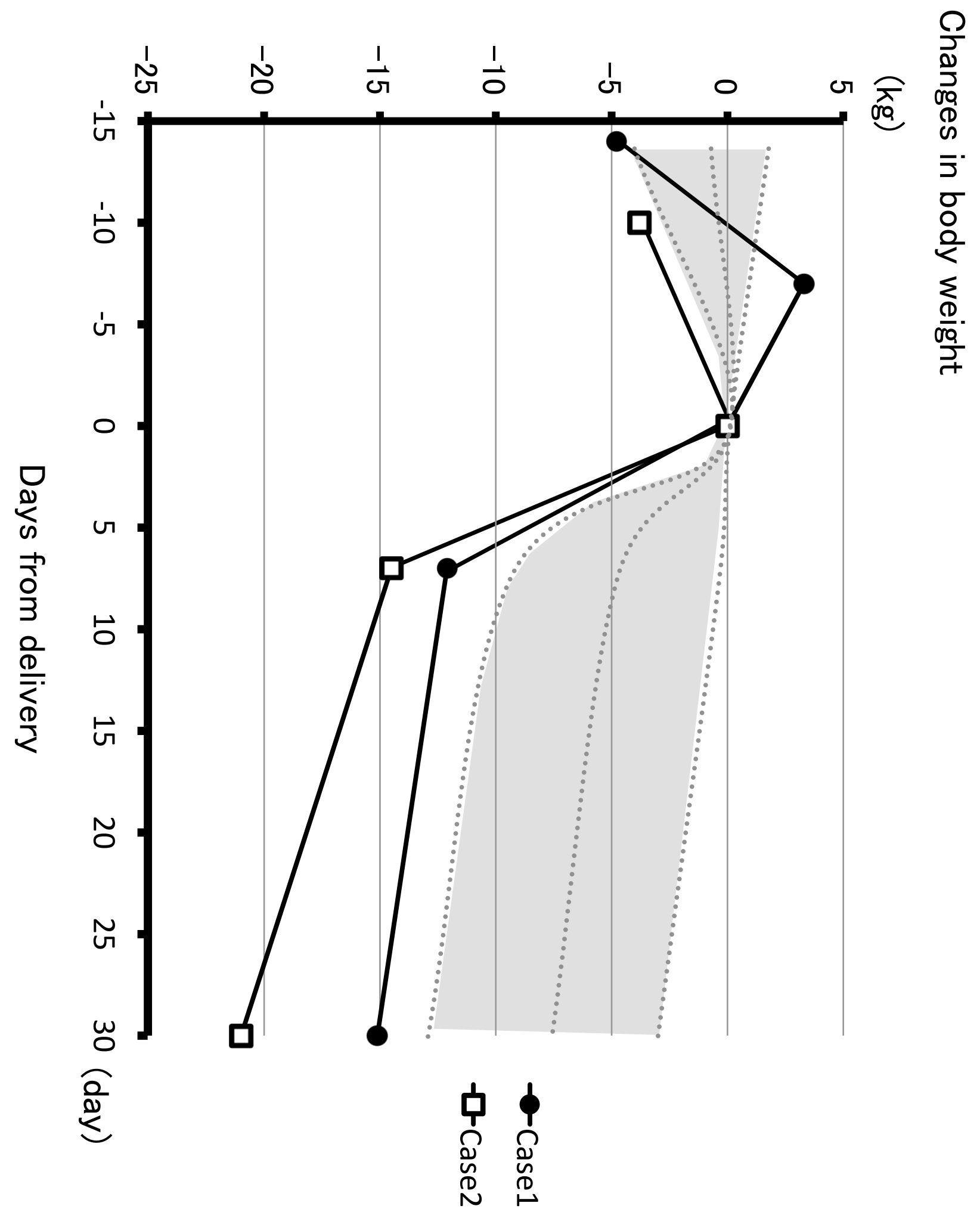


Table 1. Clinical characteristics of 11 women with eclampsia

\begin{tabular}{|c|c|c|c|c|c|c|c|c|c|c|c|}
\hline Case number & 1 & 2 & 3 & 4 & 5 & 6 & 7 & 8 & 9 & 10 & 11 \\
\hline Age (year) & 36 & 35 & 24 & 36 & 38 & 22 & 31 & 21 & 19 & 36 & 38 \\
\hline Parity & 2 & 0 & 0 & 2 & 0 & 0 & 1 & 0 & 0 & 0 & 0 \\
\hline \multicolumn{12}{|l|}{ Pre-pregnancy } \\
\hline Body weight (kg) & 54.0 & 48.0 & 78.0 & 54.6 & 55.0 & 61.0 & 56.8 & 51.0 & 52.9 & 56.0 & 49.0 \\
\hline BMI (kg/m2) & 23.7 & 18.5 & 27.3 & 22.8 & 21.8 & 24.4 & 24.0 & 21.2 & 24.8 & 21.3 & 21.5 \\
\hline \multicolumn{12}{|l|}{ At delivery } \\
\hline Gestational week & $37-3 / 7$ & $40-6 / 7$ & $36-3 / 7$ & $39-3 / 7$ & $38-3 / 7$ & $40-2 / 7$ & $41-3 / 7$ & $39-4 / 7$ & $38-1 / 7$ & $40-5 / 7$ & $40-4 / 7$ \\
\hline Body weight (kg) & 67.3 & 73.0 & 89.6 & 65.0 & 64.1 & 74.2 & 63.7 & 66.7 & 58.9 & 65.5 & 58.4 \\
\hline \multicolumn{12}{|l|}{ Time of onset } \\
\hline Hypertension* & $36-4 / 7$ & $40-5 / 7$ & $36-2 / 7$ & no & $38-3 / 7$ & $40-1 / 7$ & $41-0 / 7$ & $39-4 / 7$ & $38-1 / 7$ & $40-5 / 7$ & $40-4 / 7$ \\
\hline Proteinuria* $^{*}$ & $36-4 / 7$ & $40-5 / 7$ & $36-2 / 7$ & no & $38-3 / 7$ & no & $41-0 / 7$ & $39-4 / 7$ & no & no & no \\
\hline Eclamptic fit & $37-3 / 7$ & PP 3d & $36-3 / 7$ & PP $0.1 \mathrm{~h}$ & PP0.5h & $40-2 / 7$ & PP2.5h & PP3h & PP0.5h & $40-5 / 7$ & $40-4 / 7$ \\
\hline Mode of delivery & CS & TV & CS & CS & TV & CS & TV & TV & TV & TV & TV \\
\hline PIATD & + & + & + & + & - & + & - & + & - & - & - \\
\hline EOWG & + & + & - & - & - & - & - & - & - & - & - \\
\hline \multicolumn{12}{|l|}{ Laboratory data† } \\
\hline AST $>40 \mathrm{IU} / \mathrm{L}$ & + & + & + & - & + & - & - & + & - & - & + \\
\hline $\mathrm{LDH}>400 \mathrm{IU} / \mathrm{L}$ & + & + & + & - & + & - & - & + & - & - & - \\
\hline Platelet $<120 \times 10^{9} / \mathrm{L}$ & - & - & + & + & + & - & - & - & - & - & + \\
\hline \multicolumn{12}{|l|}{ Infant } \\
\hline Sex & male & male & female & female & male & male & male & female & male & female & male \\
\hline Weight (g) & 2,334 & 4,034 & 2,060 & 3,782 & 2,062 & 2,772 & 3,590 & 2,812 & 3,310 & 2,976 & 3,368 \\
\hline MRI & RPLS & RPLS & $\mathrm{NE}$ & $\mathrm{NE}$ & $\mathrm{NE}$ & NA & $\mathrm{NE}$ & $\mathrm{NE}$ & $\mathrm{NE}$ & NA & NA \\
\hline Sequela & none & none & none & none & none & none & none & none & none & none & $\mathrm{HP}$ \\
\hline
\end{tabular}

${ }^{*}$ Time when hypertension and/or proteinuria was seen antenatally for the first time.

Hypertension was defined as systolic blood pressure of $\geq 140 \mathrm{mmHg}$ and/or diastolic blood pressure of $\geq 90 \mathrm{mmHg}$. Proteinuria was defined as protein loss in the urine $\geq 0.3 \mathrm{~g} /$ day.

PP, postpartum; PIATD, pregnancy-induced antithrombin deficiency; EOWG, extraordinary weight gain ;CS, cesarean delivery; TV, transvaginal delivery ; HP, hypopituitarism

†Presence (+) or absence (-) of transient elevation of serum AST and LDH, and transient thrombocytopenia during 3 days prior to and 4 days after elcamptic fit.

MRI, magnetic resonance imaging; RPLS, reversible posterior leukoencephalopathy syndrome; NE, not examined; NA, no abnormality.

Brain hemorrhage was ruled out in all 11 women with brain computed tomography 
Table 2. Changes in body weight from the day of delivery according to weight gain during the last two antenatal weeks in 272 control women

\begin{tabular}{|c|c|c|c|}
\hline & \multirow{2}{*}{ Antenatal weight gain $(\mathrm{kg})$} & \multicolumn{2}{|c|}{ Postnatal weight loss (kg) } \\
\hline & & one week & four weeks \\
\hline \multicolumn{4}{|c|}{ Groups according to antenatal weight gain } \\
\hline $\begin{array}{l}<2.5 \text { th percentile } \\
\qquad(<-1.66 \mathrm{~kg}, \mathrm{n}=6)\end{array}$ & $-2.6 \pm 1.3$ & $4.1 \pm 1.3$ & $5.1 \pm 1.7$ \\
\hline $\begin{array}{l}\text { 2.5th to } 97.5 \text { th percentile } \\
\qquad(-1.66 \mathrm{~kg} \text { to } 4.01 \mathrm{~kg}, \mathrm{n}=260)\end{array}$ & $0.9 \pm 0.9$ & $4.8 \pm 2.0$ & $7.6 \pm 2.4$ \\
\hline $\begin{array}{r}>97.5 \text { th percentile } \\
(>4.01 \mathrm{~kg}, \mathrm{n}=6)\end{array}$ & $6.2 \pm 2.2$ & $6.7 \pm 1.3$ & $11.0 \pm 5.1 \S$ \\
\hline
\end{tabular}

Data are expressed as mean $\pm S D$.

$\S p<0.005$ and 0.05 vs women group with an antenatal weight gain of $<2.5$ th percentile and of 2.5 th to 97.5 th percentile, respectively. 


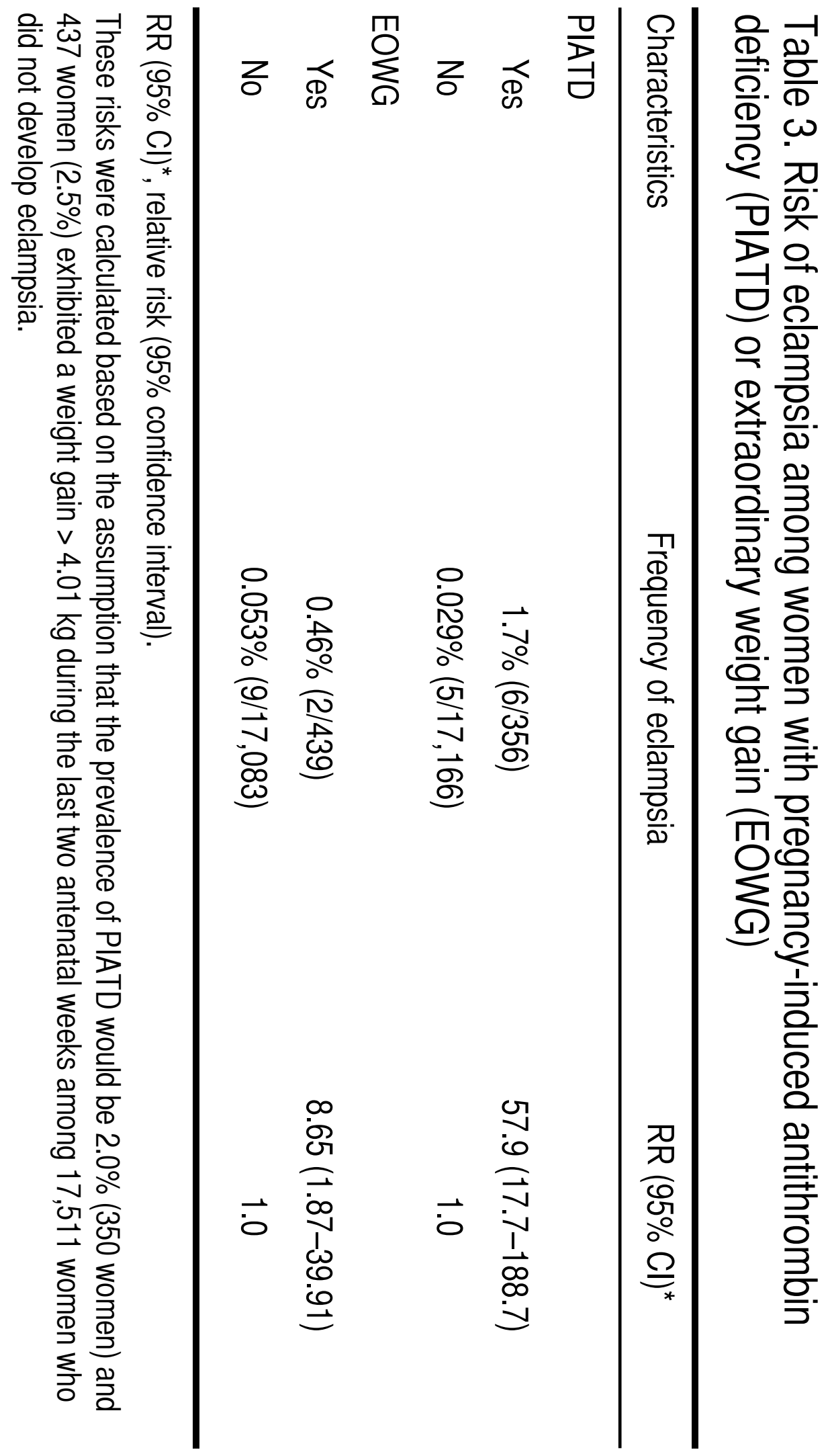

